\title{
A Corpus-Based Analysis of the Animal Images in The Wind Among the Reeds
}

\author{
ZHU Chen-shu, REN Xiao-fei \\ Jiangsu University, Zhenjiang, China
}

\begin{abstract}
The Wind Among the Reeds, written from 1889 to 1939, is regarded as one of the most remarkable poetry collections of William Butler Yeats. It altogether includes 80 poems touching upon several themes such as love, religion, dignity, and life. Yeats is one of the most distinguished Irish poets throughout the world, whose works perfectly embody the incorporation of romanticism, modernism, and occultism. It is noteworthy that in some of his poems, animals are portrayed frequently or even taken as the title of a poem, such as bird, fish, swan and so on. Therefore, this essay attempts to study the meaning of animal images of this poetry anthology in terms of different writing phases of Yeats. Firstly, the author builds the corpus of The Wind Among the Reeds and employs corpus search software Ant Conc to check the number and distribution of the animal image. Next, the author focuses on certain prominent images and investigates them further by analyzing the concordance lines of them. Thirdly, according to the result of distribution information, the author also attaches importance to the phenomenon of image combination in the poetry and then explores its function and effect. To conclude, by exploring the animal image in The Wind Among the Reeds, a deeper understanding of the poetry and the writing style of the poet will be gained on another level. What is more, a more direct and objective data is provided through the method of corpus and its relevant software, thereupon a new research approach is introduced.
\end{abstract}

Keywords: corpus, animal images, The Wind Among the Reeds

\section{Introduction}

\section{Introduction of William Butler Yeats}

William Butler Yeats was one of the most distinguished Irish poets, playwrights, and essayists, as well as one of the foremost figures of literary world in 20th century. Born in Dublin, Yeats spent his childhood holidays in County Sligo and studied poetry in his youth. In his later life, he wrote a considerable number of poems which exerted far-reaching impacts on the whole world. Firstly influenced by Shelly, John Butler Yeats as well as the Romantic background, Yeats began to take interest in aestheticism and romanticism. Afterwards, he incorporated the Irish tales and folklore into his writing of love poems. Later at the beginning of 20th century, due to the tremendous change of social situation and world pattern, Yeats began to turn to modernism by using symbolism to reflect the unsatisfactory and brutal life. In his later years, Yeats was obsessed with occultism and became objective about his personal feelings and social reality, thus his individual writing style was finally formed.

ZHU Chen-shu, Postgraduate Student, School of Foreign Languages, Jiangsu University. REN Xiao-fei, Doctor, Professor, International Office, Jiangsu University. 
Therefore, his work is an ideal combination of profound thoughts, rich contents, and universal influence. In December 1923, he was awarded the Nobel Prize in Literature as the first Irishman so honoured for what the Nobel Committee described as "inspired poetry, which in a highly artistic form gives expression to the spirit of a whole nation".

\section{Introduction to The Wind Among the Reeds}

The Wind Among the Reeds, being considered as one of the most renowned collection of poems of Yeats, has aroused extensive attention of experts at home and abroad. It is selected from twelve poetry anthologies includes Crossways, The Rose, The Wind Among the Reeds, The Seven Woods, The Green Helmet and Other Poems, Responsibilities, The Wild Swans at Coole, Michael Robartes and the Dancer, The Tower, The Winding Stair and Other Poems, New Poems, and Last Poems. As is written from 1889 to 1939, those poems could be deemed as a collection of works of Yeats written at different periods. Thus, this paper will explore the meaning of animal images at different stages as well as trace the change of writing style of the poet under the assistance of the corpus search software. By employing Ant Conc, the data details of animal images will be gained and the categories of them will also be divided.

What calls for special attention is that the study object of this essay, The Wind Among the Reeds, uses the Chinese translation version by Ai Mei as standard, which is different from the original version to some extent.

\section{Literature Review}

Up to now, several scholars and experts spare no efforts to study the images of Yeats's poems. Broadly speaking, the research mainly focuses on the nature image or the image of certain plant in the poetry. For example, YANG Sheng-hua writes Natural Images and View of Time in Yeats's Poetry where he studies the natural images which embody Yeats's special view of time and then explains the mystification, sanctification and spatialization of time. Similarly, in The Nature Images in William Butler Yeats' Poetry, GAO Yuan tries to reveal the pursuit of nationalism, love, and art of Yeats through interpreting the meaning of nature images at different periods. What is more, DENG Shu-zhen explores the symbolic meanings of the image of dew while GAN Wen-ting investigates the image of swan which reflects the change of the poet's value of love. The image of rose in particular, there are numerous studies focus on it. However, there are few systematic researches about the animal image in Yeats's poetry currently. Therefore, the author attempts to make a general research about the image of animals through which a new study perspective will be gained. Nonetheless, this essay is just a primary analysis of one collection of Yeats's poetry. It only chooses eighty poems for investigation and lacks a solid theoretical framework. Therefore, more works are expected to be explored and further researches are expected to be carried out.

\section{The Animal Image: Another Key to the Poetry}

\section{The Definition of Animal Image}

Image is a special category of artistic imagination as well as a unique kind of rhetoric devices which is widely used in poetry, fiction, and prose. In China, image is deemed as the combination of outer concrete entity and inner abstract feelings. LIU Xie firstly used "image" as a concept of literature theory in The Literary Mind and the Carving of Dragons, signaling the creation of "image" in Chinese classical poetics. While in the western world, image refers to the replica before the Renaissance. Later, the poet Pound (1913) defined that "an

1 See from http://www.nobelprize.org/nobel_prizes/literature/laureates/1923/. 
image is that which presents an intellectual and emotional complex in an instant of time".

While animal image, a special category of image, occupies a crucial status for conveying emotions and feelings in poetry. It is the fusion of human mind and zoomorphism through which man could express his ideas, beliefs, or thoughts. Since ancient times, animal image, especially those related with myth, has been worshiped by the human. As animals not only provide coats and food for human, but also become friends and companions of human. With the development of human civilization, the animal image has transferred from simple totem symbols to the tool of cultural belief and carrier of ancient tradition. Therefore, it can be seen that the animal image is a miniature of alien civilization as well as a bridge to exotic culture.

\section{The Category of Animal Image}

In terms of different standards of classification, image can be divided into different categories. For example, according to the property, images can be divided into (1) natural images, such as flowers, grass and trees; (2) personal images, such as drinking down sorrow, admiring the beauty of flowers, and yelling to the sky; (3) fantasy images, such as mythical creatures and mythological figures. Based on the classification of sensory perception, the image can be divided into: (1) visual images; (2) auditory image; (3) tactile images; (4) the image of synesthesia.

It is the same case with the classification of animal image. Based on the artistic method, the animal image could briefly be divided into (1) descriptive imagery; (2) figurative imagery; (3) symbolic imagery; and (4) lyrical imagery. Due to the change of writing style of Yeats, the meaning of images will alter correspondingly in the poem thus it will be difficult to analyze the animal images from their artistic functions as a whole. In consequence, the taxonomy of animals in this paper will base on the species of animals in this essay, namely, birds, beasts, insects, fish, and virtual animals.

\section{The Animal Images in The Wind Among the Reeds}

In The Wind Among the Reeds, there are altogether 43 different kinds of animals. According to the general division standard, those animals can roughly be divided into five kinds. By labeling those animals in the text, their categories and frequencies are obtained through the regular expression of Ant Conc (see Table 1).

Table 1

The Categories of Animals and Their Frequencies

\begin{tabular}{ll}
\hline Category & Number \\
\hline Birds & 17 \\
Beats & 13 \\
Insects & 5 \\
Fish & 4 \\
Virtual animals & 4 \\
\hline
\end{tabular}

Based on the data above, we could make a rough assumption that birds and fish are usually lovely, favorable, and energetic, which will mostly be used to create a romantic atmosphere. Moreover, beats are mighty and strong and the insects are insignificant which could stand for the contrast between the weak countrymen and powerful political forces at that time. In addition, virtual animals could be employed to add the color of occultism in the late poems of Yeats. Anyway, it is just a primary presumption from solely one table. The more reliable and detailed analysis will be made in the following paragraphs. 
Moreover, the author also chooses some animals which are of high frequency and makes the table below. Since the investigated poetry is a collection of small quantity, only eighty poems, so any animal which appears prominently should be drawn attention to.

Table 2

The Animals of High Frequency in The Wind Among the Reeds

\begin{tabular}{ll}
\hline Category & Frequency \\
\hline Bird & 9 \\
Hare & 7 \\
Horse & 4 \\
Swan & 4 \\
Fly & 3 \\
Mice & 3 \\
\hline
\end{tabular}

It can be seen that "bird" and "hare" appear most frequently in the poems of Yeats. Besides, horse, swan, fly and ice are also important images among all the animal images. Therefore, a detailed analysis about them will be made in the next sections.

\section{The Animal Images in the Early Period}

This period started from 1883 to 1899 during which the author was deeply influenced by romanticism and aestheticism. At that time, Yeats made a thorough study about the Irish legends and folklores and included them in his poems and proses through recomposition or adaptation. It was during such times that Yeats gradually became a romanticist and aestheticist.

From the collected data, the category of bird image appears most frequently in this period, including peahens, parrot, linnet, sparrow, bird, and heron. Moreover, it is also found that "bird" and "sparrow" appear as independent images and the rest all show up as combination images. Below the author will choose one example from each one for detailed analysis.

To make clear here, the independent image refers to the image which can form or symbolize one meaning all by itself. In this case, the author selects to analyze the image "bird" which is used prominently during the early writing stage of Yeats. According to this situation, the author uses Ant Conc to obtain the concordance lines of "bird" in order to trace its distribution in the poetry.

Table 3

The Concordance Lines of "Bird"

\begin{tabular}{ll}
\hline Hit & KWIC \\
\hline 1 & The White Birds (the title) \\
3 & my beloved, white birds on the foam of the sea! \\
4 & For I would we were changed to white birds on the wandering foam: \\
\hline
\end{tabular}

From the table above, it is evident that the "birds" are closely linked with the "beloved" in the poem. To be more specific, the white birds could stand for the poet and his lover. In addition, Yeats expressed his love to Maud Gonne and expected the eternal and pure love. Meanwhile he wished that he could stay with his lover and they could live happily forever seclude form the world. Therefore, birds symbolize love and create a romantic atmosphere along with other images. As there are several researches about this poem, it would be superfluous to dwell on its connotation any more. 
On the other side, some images occur with other images together to express meanings. In other words, only one of them does not stand for any sense. For example, in The Lake Isle of Innisfree, the honeybee, cricket, and linnet appear together. They work together to draw a natural, gorgeous, and peaceful picture. At this point, the elements of romance are quite obvious here. Moreover, the poet here attempts to create a natural and comfortable atmosphere, expressing his yearning for the simple life and unsophisticated world. While the honeybee, cricket, and linnet are all the products of the nature which are lovely, adorable, energetic, and vigorous. Therefore, they have taken on the directors of romance gradually in this film.

To conclude, either independent image or combined image, bird image or insect image, those animal images in this period were mainly closely related with romance. They were employed by the poet to reach his romantic goal.

\section{The Animal Images in the Middle Period}

This phase lasted from the beginning of the 20th Century to the end of the First World War. At that time, the poet was confronted with the non-ideal and brutal social facts. Then he began to change from romanticism to modernism with symbolic techniques, his new mighty tool. As time went by, the poet gradually abandoned the traditional writing style and his language became more straightforward. During this period of time, occultism played an indispensable part in his transformation of the style of poetry.

As mentioned previously, the phenomenon of combination of images is found in the poetry. In this case, it is two kinds of birds, peewit and curlew that occur at the same time in the poetry twice. See The Withering of the Boughs:

I cried when the moon was murmuring to the birds:

"Let peewit call and curlew cry where they will, peewit:

I long for your merry and tender and pitiful words,

For the roads are unending, and there is no place to my mind.”

The honey-pale moon lay low on the sleepy hill,

And I fell asleep upon lonely Echtge of streams.

...

I know of the sleepy country, where swans fly round

Coupled with golden chains, and sing as they fly.

A king and a queen are wandering there, and the sound

Has made them so happy and hopeless, so deaf and so blind

With wisdom, they wander till all the years have gone by;

I know, and the curlew and peewit on Echtge of streams.

No boughs have withered because of the wintry wind;

The boughs have withered because I have told them my dreams. (Yeats, 2004, p. 72)

Therefore, it can be concluded that the "peewit" and "curlew" are the combination of images in this poem. They appear together in order to be in contrast with the situation of the poet. They stand for merry, tender, and carefreeness. Furthermore, their combination can also be interpreted as the beautiful love which the poet purses for all his life time. Through this technique, the poet bonds the images together so as to provide a vivid picture to the readers. They are arranged based on the aesthetic principles of the poet and thus the feelings of the poet are pervaded. Through the effect of contrast, symbolism, or analogy they achieve, these images become the re-creation of the poet. 
As is mentioned in the introduction part, influenced by Eastern methodologies and occultism, the writing style of Yeats started to change since 1885 when he and his friends founded the Dublin Hermetic Order. That was why during that period, a special kind of animal image appeared in the poems of Yeats, that was, the virtual animals. Normally they are products of fairy tales or religious legends. By employing these characters, the poet takes aim at putting on the mysterious coat for his poems. To be more concrete, the virtual animal serves as a prophet, supernaturalist, god or demigod. It is found that there are two virtual animals that occur three times in this poetry. One is the centaur, and the other is the dragon. Take the "centaur" in the poem for instance. In Lines Written in Dejection, it says:

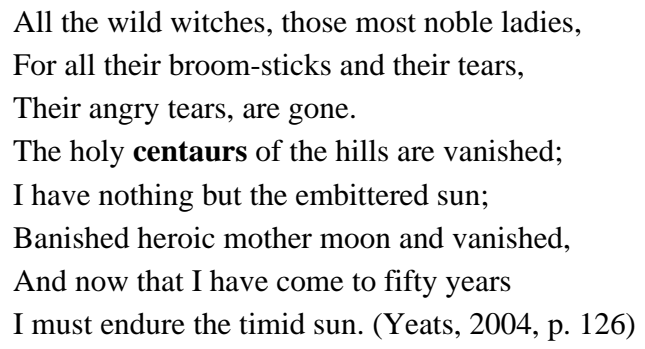

The centaur in the poem refers to a mythological creature with the upper body of a human and the lower body of a horse. By complaining the non-existent witch and centaur, the poet expressed his boredom of the routine life. Or on the other hand, he is just lamenting that the beauty of past is gone. Thus it may inspire the reader to trace back to the ancient times or envision the mythical stuff. Anyway, by putting the witch and centaur together and comparing them with the sun, the amazing imagination of the poet is quite obvious. Furthermore, these images also prove that the poet has realized his wish for a pure and peaceful world is unreal.

To sum up, in the middle writing stage of Yeats, the images, especially the animal images, are tinted with the color of symbolism and occultism. They indicate that the poet is no longer intoxicated with his fantasy dreams and the poet begins to confront the real life with courage and bravery.

\section{The Animal Images in the Late Period}

This stage began from 1919 to the late 30s when Yeats finally formed his individual style and reached a union of life wisdom and personal feelings, symbolic technique and realistic approach. The state of mind was rather detached, so the poems were endowed with philosophical significance.

Starting from the combination of image, it is found that several animal images flock together in one section of the poem, namely, Easter 1916:

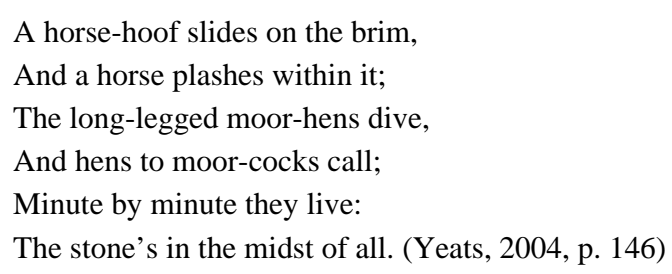

In this stanza, horse, moor-hen, hen, and moor-cock altogether compose a picture which is attractive and appealing. Related with the historical background, this poem was written three months after the leaders of the uprising were executed. The picture the poet drew here is used to convey his exclamation and lament. On one side, he extolled the heroes who fought for the freedom of the Irish people and admired their bravery and 
perseverance. On the other side, he was also doubt about the bloody way to carry on the cause. Therefore, the attitude of the poet here actually was contradictory and ambivalent. Furthermore, while depicting a natural picture, the poet also put a disharmonious stone here, midst of all. The risers could be as unflinching as the stone or as cold as the stone. It turned out that the shadow of contract, uncertainty and aloofness was clearly reflected in this poem.

Meanwhile, there is also a tiny but intriguing animal image that appears frequently in the last stage, namely, the fly. By employing Ant Conc again, the concordance lines of the "fly" are obtained.

Table 4

The Concordance Lines of "Fly"

\begin{tabular}{ll}
\hline Hit & KWIC \\
\hline 1 & Long-Legged Fly \\
2 & Like a long-legged fly upon the stream \\
3 & Like a long-legged fly upon the stream \\
4 & Like a long-legged fly upon the stream \\
\hline
\end{tabular}

It is discovered $d$ that the poet used the "fly" as the title of the poem and then used repetition about "fly" to make a conclusion of each stanza. Take the first paragraph for example, it says that:

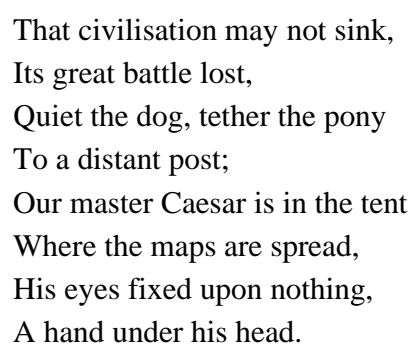

Generally speaking, the fly is an annoying and unimpressive animal for the common people. However, the poet here regarded it as noble as the apple blossom and used it to refer to the most delicate image. In the stanza above, the poet skillfully linked Caesar with the fly by using a metaphor. First of all, the fly had a symbolic meaning itself, which stood for a tranquil and clear state of mind. Then the poet compared the situation that Caesar was in meditation with the picture that the fly was lingering on the stream. Finally, the status and position of the fly were greatly improved through an analogy.

In the selected poem above, the mighty power of imagination of the poet is beyond doubt. Meanwhile, the individual style of Yeats is also manifested here. It seems that he has reached the ideological level of detachment: everything is important while nothing is significant. Tiny things could be lofty while major stuff could be insignificant. Lastly, the poet is able to use the techniques (such as symbolism and contrast) proficiently and compound them together harmoniously.

\section{Conclusion}

To sum up, this paper chooses the animal images of The Wind Among the Reeds as the study objet and uses corpus as research tool. By studying the meanings of animal images at different times, the distribution of 
the animal images is revealed and the preference for using the image of birds and beats of the poet in writing is also found. Moreover, it turns out that Yeats is also fond of use combination of images for expression or description. In short, this paper attempts to analyze the poetry from the angel of animal images and explores its connotation on another side. It helps readers form an intuitional impression of the text through the method of corpus and paves the way for the further study of animal image in The Wind Among the Reeds.

However, this research only makes a general study about the animal images of one poetry collection of Yeats. In addition, it just analyzes some simple data obtained directly from Ant Conc. Therefore, numerous researches about the animal images in Yeats's poetry are remained to be done. To be more specific, the relevant study could include all the poems of Yeats as study object, so a more macroscopic and objective view of the animal images will be gained. Besides, the classification of animal images in Yeats's poetry is expected to be divided more accurately and scientifically. Lastly, more scientific research methods and advanced research theories are remained to be employed for any further study of this poetry.

\section{References}

Ai, M. (2006). The wind among the reeds. Tianjin: Tianjin Education Publishing House.

Centaur. (n.d.). Retrieved from https://en.wikipedia.org/wiki/Centaur

DENG, S. Z. (2010). On dew image of Yeats's lyrics. Journal of Yibin University, 10(2), 55.

DING, Chen. (2006). The images of animals in book of songs (Master thesis, Suzhou University).

GAN, W. T. (2012). The change of the swan image in the love poems of Yeats. Journal of Yangtze University (Social Science), 35(4), 27.

GAO, Y. (2012). The nature images in William Butler Yeats’ poetry (Master thesis, Jiangxi Normal University).

LI, X. Y., \& Li Z. S. (2015). On the animal images in Nagarjuna's gnomic verses and Sakya gnomic verses plus some examples of English translation. Translation Forum, 1(74), 46.

LIANG, M. C., LI, W. Z., \& XU, J. J. (2010). Using corpora: A practical coursebook. Beijing: Foreign Language Teaching and Research Press.

LIU, X. (2000). The literary mind and the carving of dragons. Beijing: People’s Literature Publishing House.

Pound, E. (1913). A retrospect. Poetry, I, 6.

The Nobel Prize in Literature 1923. (n.d.). Retrieved from http://www.nobelprize.org/nobel_prizes/literature/laureates/1923/

WANG, C. X. (2011). An ecological reading of Yeats' poems (Master thesis, North China Electric Power University).

WANG, L. (2011). An analysis of the evolution of the images in Yeats's poetry. Journal of Changchun University, 6, 8.

YANG, S. H. (2015). Natural images and view of time in Yeats's poetry. Journal of China West Normal University (Social Sciences), 1, 99.

Yeats, W. B. (2004). The wind among the reeds. (LI, L. W., Trans.). Beijing: China Social Sciences Publishing House.

ZHANG, S. H. (2010). The study of animal images in book of songs (Master thesis, Qufu Normal University).

威廉 - 巴 特勒 - 叶芝 (William Butler Yeats). (n.d.). Retrieved from http://baike.baidu.com/link?url=e-gba_sjj0do0V0zuXNZZfsnyBRjmmARollhpLBD74OX08-rDs_N7_UcNl7p0MB6DESnk -d-y_1pfhS3N4-QkCa6eoafZLCGEbhuQ1FUK4B34evFZsFiGN9jny1ji9n 